\title{
Selected leadership traits as determinants of leadership effectiveness in Nigerian sports industry
}

\author{
Olajide, O. A. ${ }^{11}$
}

\begin{abstract}
The purpose of this study is to establish whether some selected leadership traits (integration, intelligence, integrity and professionalism) are determinants of leadership effectiveness in Nigerian sports industry. The participants for the study consist of 1,826 sports administrators and organisers who were purposively and randomly sampled from 13 randomly selected states of Nigeria. A self-developed, validated and reliable questionnaire (reliability of 0.92 ) is used for data collection. It is established that Integration $[\mathrm{B}=0.030$, Beta $=0.004, \mathrm{t}=0.182, \mathrm{P}>0.05]$ do not significantly determine leadership effectiveness, while Intelligence $[\mathrm{B}=0.210$, $\mathrm{Beta}=0.084$, $\mathrm{t}=3.593, \mathrm{P}<0.05]$, Integrity $[\mathrm{B}=0.363$, Beta $=0.129, \mathrm{t}=5.425, \mathrm{P}<0.05]$, and Professionalism $[\mathrm{B}=0.316$, $\mathrm{Beta}=0.114, \mathrm{t}=4.769, \mathrm{P}<0.05]$ determine leadership effectiveness in Nigerian sports industry. Consequent upon these findings, the researcher posits that traits like intelligence; integrity professionalism and even integration should be possessed and exhibited by those providing leadership in Nigerian sports industry in order to be effective.
\end{abstract}

Keywords leadership traits, leadership effectiveness, sports industry

\section{Introduction}

The Nigerian sports industry has suffered a lot of set backs in recent times especially in international competitions. The performances of Nigerian athletes in international championships for example, the 2002 Commonwealth Games, 2004 Olympics, the inability of Nigeria to go beyond the first round in the subsequent world cup championships after her impressive performance in 1994 world cup in USA, and the eventual failure of Nigeria to qualify for 2006 world cup Championships are evidences of the dwindling fortune of the Nigerian nation in sports. This has been a subject of great concern to Nigerians particularly the athletes, the sports administrators and the government.

This concern culminated in various researches embarked upon by the academics in the field of sports administration most of which center on lack of facilities, equipment, supplies, qualified personnel, funds and a host of others as reasons for the dwindling fortune of sports in Nigeria ( Adesanya 1989; Fasan 1989; Asagba 1992; Orunabuka 1998; and Omolawon, 2000 ). The government (probably in response to the findings of these researches) has stepped up the provision of the variables of sports development mentioned above. For instance, in the area of sports facilities, many state governments have built stadiums of international standards. The state

${ }^{11}$ Dr. Olajide, O. A. lectures at the Physical and Health Education Department, Federal College of Education, Yola, Adamawa State, Nigeria. 
of the art National Stadium in Abuja can not but be mentioned as an example of the deliberate effort of the Nigerian government to stem the tide of the dwindling fortune of sports in Nigeria.

Going by the failures Nigeria has suffered in spots in recent times, one can safely postulate that all these efforts have not produced commensurate excellence in sports by Nigerian athletes in international championships. Several authors (Awosika 1995; Ajiduah 2001; Duru 2001; and Olanipekun 2002) attributed the poor performance of Nigerian athletes to poor leadership. This points to the fact that holistic sports development in Nigeria does not end with the provision of the parameters mentioned above alone but must be supported by leadership effectiveness if the desired result must be achieved. It is therefore necessary to find out whether certain leadership traits determine leadership effectiveness in the Nigerian sports industry.

\section{Leadership and leadership effectiveness: An overview.}

Leadership is imperative for modelling a group of people into a team, shaping them into a force that serves as a competitive business advantage. Leaders know how to make people function in a collaborative fashion, and how to motivate them to excel in their performance. Leaders also know how to balance the individual members' quest with the goal of an outcome that exceeds the sum of individual inputs. Leaders require that their team members forego the quest to personal best in concert with the team effort (Adair, 2002)

Warren (2000) defined leadership as a complex process by which a person influences others to accomplish a mission, task, or objectives and directs the organisation in a way that makes it more cohesive and coherent. Leadership according to Babajide (2000) is a process of influencing the activities of an individual or a group's efforts towards goal achievement in a given situation. In essence, leadership involves accomplishing goals with or through people. The important thing to note in this definition is that leadership cannot exist in isolation there must be the leader and the follower. Leadership involves change in the individual being led. It influences a process by effectively changing the behavior of others.

Many people believe that leadership is simply being the first, biggest or most powerful. Leadership in organisation has a different and more meaningful definition. Very simply put, a leader is interpreted as someone who sets direction in an effort and influences people to follow that direction. McNamara (1999) in support of this statement affirmed that leading is establishing direction and influencing others to follow that direction. He further stated that there are many variations and different areas of emphasis to this very simple definition as experts have asserted that whether one is an executive or an entry-level worker in his/her organisation, it is critical for one to have strong skills in leadership.

Akintunde (2001) submitted that, to lead is to guide, conduct, direct and preside. It is the duty of a leader to help a group achieve objectives with the maximum application of its capacities. A leader does not stand behind a group to push, he places himself before the group as he facilitates progress and inspires the group to accomplish organisational goals. Sequel to this, leadership can be considered as the process of influencing others to get the job done effectively over a sustained period of time. Influence is described as the process of affecting the potential behavior of others.

Bennis (1995) identified four leadership competencies that an effective leader should possess. They are: 
a. Management of attention through a set of intension, or a vision in a sense of outcome, goal or direction.

b. Meaning management by making dreams predictable to others and aligning people with dreams through articulate communication skill. It also involves making ideas real to others while supporting their realization.

c. Trust management vis - a - viz consistency reliability and focus.

d. Self-management by involving learning and mastery to the point of

regarding failure as only mistakes that provides feedback and reveals the next line of action.

Leadership effectiveness according to Akintunde (2001) implies that the person in position of authority should respect and always put into consideration the goals of the organisation and welfare of the personnel in the organisation. Leadership effectiveness was described by Babajide (2000) as the acknowledged ability of a manager to guide a group towards goal achievement. Godon (2002) stated that leading others is not simply a matter of style, or following some how-to guides or recipes. Ineffectiveness of leaders according to him seldom results from a lack of know-how or how-to, nor it is typically due to inadequate managerial skills. Leadership he contends is even not about creating a vision. It is about creating conditions under which all followers can perform independently toward a common objective.

From the foregoing, leadership effective simply connotes the ability of a leader to channel and harness the human and material resources at his or her disposal towards the attainment of the set goals of an organisation. The extent to which a leader is able to do this determines the level of his or her effectiveness.

\section{Attributes/Qualities that enhance Leadership effectiveness}

Leadership effectiveness is enhanced by certain qualities or traits. These according to Ituh (1992) include; administrative mind, integrity, ability to instill good human relations, ability to make decisions, health and fitness for the job, understanding the work, command of administrative techniques and intellectual capacity.

Ikhioya (2001) submitted that the under listed qualities enhance successful leadership - sound education, technical/administrative education, leadership, communication, organisational policies, work ethics, target setting, positive work influence, behavioral consistency, knowledge and skill acquisition, honesty, respect and self/ organisational evaluation.

Conclusively, leadership effectiveness is the ability of a leader to guide, manage and organise or co-ordinate a group of people to optimally achieve the set goals of an organisation. In view of the dwindling fortune of sports in Nigeria, despite the efforts of the academics and the government in proffering solutions, and the fact that even when all the parameters of sports development are provided in adequate proportions the need to properly manage and harness these human and material resources in order to make them contribute positively to sports development and excellence hinges on the leadership proficiency of the sports administrator. 


\section{Purpose of study and Research Hypotheses}

This study was designed to establish whether or not some selected traits are determinants of leadership effectiveness in the Nigerian sports industry. The achieve this, the following hypotheses were formulated to guide the study:

1. Intelligence will not significantly determine leadership effectiveness in Nigerian sports industry.

2. Integrity will not significantly determine leadership effectiveness in Nigerian sports industry.

3. Integration will not significantly determine leadership effectiveness in Nigerian sports industry.

4. Professionalism will not significantly determine leadership effectiveness in Nigerian sports industry.

\section{Methodology}

The descriptive survey research of the ex-post-facto type is used for this study.

\section{Population}

The population for the study consists of all sports federation chairmen and secretaries of the Federal Ministry of Sports and Social Development (FMS-SD), all states Directors of sports and their administrative heads, all states sports associations' chairmen, secretaries and members, and all national and state coaches.

\section{Sample}

A random sampling technique of shuffling cards method is used select two state sports councils from each geographical zones in Nigeria, national and state coaches and sports association members, while the purposive sampling technique is used to select the FMS-SD, sports federation chairmen and secretaries, Directors of sports, administrative heads, chairmen and secretaries of sports associations in selected sports councils. The total sample size of 1,826 respondents is finally used for the study.

\section{Instrumentation}

The main instrument used for this study is a modified and validated questionnaire named Determinants of Leadership Effectiveness Questionnaire (DLEQ). The Questionnaire (DLEQ) was made up of two sections. Section A focused on the personal data of the respondents, while section $\mathrm{B}$ centred on criteria for measuring leadership effectiveness and the variables under study. The questionnaire was a close ended type designed in line with the modified Likert scale technique of summated rating with weight allotted so as to enable the respondents indicate the extent of agreement or disagreement with the questions supplied. Thus, the response was on four- point scale viz.

\begin{tabular}{llll} 
Degree of response & & \multicolumn{3}{c}{ Points } \\
Strongly Agree & - & (SA) & 4 \\
Agree & - & (A) & 3 \\
Disagree & - & (D) & 2 \\
Strongly Disagree & - & (SD) & 1
\end{tabular}


The reliability of the instrument was determined by the use of Crombach Alpha-Coefficient, which produced a reliability coefficient of 0.92 .

\section{Data Collection and Analyses}

The researcher personally administered the questionnaire with the aid of a research assistant in each of the twelve states of the federation selected for the study and the FMS-SD. The inferential statistic of multiple regression is used to determine the level of contribution of each independent variable to the prediction of the dependent variable. The decision criterion for rejection or acceptance of hypotheses of the study is set at 0.05 alpha level.

\section{Analysis of Data and Discussion of Findings}

The results of the data analysis statistical tests on the hypotheses are presented in Tables 1, 2, 3 and 4 and discussion of findings follows after each table. Table 1 presents the summary of multiple regression on intelligence as a determinant of leadership effectiveness among sports administrators and organisers in Nigeria.

Table 1 Relative contribution of intelligence to the determination of leadership effectiveness

\begin{tabular}{|c|c|c|c|c|c|}
\hline B & SEB & Beta & T-Ratio & p & RMK \\
\hline 0.210 & 0.059 & 0.084 & 3.539 & 0.000 & $\mathrm{~S}^{*}$ \\
\hline
\end{tabular}

Table 1 shows that the b-value of intelligence, which is 0.210 , indicates the level of its contribution to the determination of leadership effectiveness. The standardized regression weight (Beta) of intelligence is 0.084 , which is the level of the relationship of the determinant variable to leadership effectiveness. The $\mathrm{t}=3.539$ which is statistically significant at $\mathrm{p}=0.000$. Since $0.000<0.05$, the null hypothesis is rejected and an alternative hypothesis which states that intelligence will significantly determine leadership effectiveness in Nigerian sports industry is accepted.

This finding is in conformity with the opinion of Ituh (1992) that an administrator should be intelligent because traits such as absent-mindedness, non-punctuality and inability to make decisions constitute poor leadership. In the same vein, Horine (1999) postulated that intelligence enables a leader the have a high level of common sense in order to synthesize complex situations and react in an orderly manner. This he concluded enhances leadership effectiveness.

To further give credence to the finding of this study, Ipinmoroti (2000) pointed out that the only personal quality or trait that has any concrete association with leadership effectiveness is the leader's intelligence. Stressing the relevance of intelligence to leadership effectiveness, Wuest and Bucher (1999) opined that intelligence refers to the ability to appraise situations and then be able to conceptualise the appropriate course or action. They stressed that leaders sho have this kind of intelligence are able to sense relationsHip!aeong various aspects of the organisation, use past experiences when pertinent tk solve pres\%nt problems, and See a line of wiSe action that needs to be taken. Leaders who have this kind of intelligence have imagination 'nd sound Reasoning powers. Sequel to these submissions, which support the finding of this study, the 2edevance of intelligence to lea\$ership effectiveness, 85 has been established beyond any doubt. 
Selected leadership traits as determinants of leadership effectiveness in Nigerian sports industry

Olajide, O. A.

Table 2 Relative contribution of integrity to the determination of leadership effectiveness

\begin{tabular}{|c|c|c|c|c|c|}
\hline B & SEB & Beta & T-Ratio & p & RMK \\
\hline 0.363 & 0.067 & 0.129 & 5.425 & 0.000 & $\mathrm{~S}^{*}$ \\
\hline
\end{tabular}

$\mathrm{S} \rightarrow$ Significant at $\mathrm{p}<0.05 ; \mathrm{NS} \rightarrow$ Significant at $\mathrm{p}>0.05$

Table 2 reveals that the b-value of integrity is 0.363 , which is the level of the contribution of integrity to the determination of leadership effectiveness. While its standardized regression weight (Beta) is 0.129 , which is a reflection of the level of the relationship between integrity and leadership effectiveness. The $t=5.425$ which is statistically significant at $\square=0.000$. Since 0.000 $<0.05$, the null hypothesis is rejected in favour of an alternative hypothesis which states that integrity will significantly determine leadership effectiveness in Nigerian sports industry is accepted.

This finding is in line with the submission of Ituh (1995) that the power to inspire the entire staff, have their cooperation and achieve the purposes of the programme depends on the leader's integrity. In other words, integrity of a leader enhances his leadership effectiveness. In the same vein Wuest and Bucher (1999) writing on the relationship between integrity and leadership effectiveness submitted that leaders who have integrity act in accordance with the high expectations of their constituency and are thereby effective because they can be trusted by the people they provide leadership for. They further maintained that effective leaders have a strong sense of ethics and moral values. They remain firmly committed to their beliefs and never compromise their values.

The finding of this study on integrity as a determinant of leadership effectiveness and the opinions of the authors cited to back up the finding point to the fact that leaders should possess integrity in order to be effective.

Table 3 Relative contribution of integration to the determination of leadership effectiveness.

\begin{tabular}{|c|c|c|c|c|c|}
\hline B & SEB & Beta & T-Ratio & p & RMK \\
\hline 0.03 & 0.047 & 0.004 & 0.182 & 0.856 & $\mathrm{NS}^{* *}$ \\
\hline
\end{tabular}

Table 3 reveals that the b-value of integration is 0.03 indicating the level of its contribution to the determination of leadership effectiveness. The standardized regression weight (Beta) of integration is 0.004 , which shows the level of the relationship between integration and leadership effectiveness. The $t=0.182$ which is statistically significant at $p=0.856$. Since $0.856>0.05$, the null hypothesis, which states that integration, will not significantly determine leadership effectiveness in Nigerian sports industry is hereby accepted. 
This finding is at variance with the opinion of Fred (1996) that within the staff in an organisation, integration occurs when the leader maintains a closely-knit organisation and that this is very necessary if an organisation will achieve its aims. He concluded that leaders who polarize their organisation are non-achievers. This opinion affirms that integration is necessary for leadership effectiveness.

This finding also contradicts the opinion of Wuest and Bucher (1999) that effective leaders create a shared vision, foster commitment and cooperation, integrate diverse views and share leadership by delegating, which gives every body a sense of belonging. They further stated that effective leaders delegate wisely, giving group members tasks to complete and responsibilities to fulfil.

Though this finding suggests that integration will not significantly determine leadership effectiveness in Nigerian sports industry, one can not conclude that integration is not contributory to leadership effectiveness going by the Beta value of 0.004 which shows that integration is related to leadership effectiveness and the $b$-value of 0.03 which confirms the level of the contribution of the determinant variable to the determination of leadership effectiveness when taken together with other determinand variables.

Despite the fact that the relative contribution of integration to the determinat)on of leadership effectiveness was not statistically significant, the relevance of integration to leadership effectiveness cannot be overemphasized as submitted by the authors cited above. For a leader to be effective he has to see the entire staff members as one big family, do all that will foster unity and cooperation among them and avoid any form of discrimination or favouritism as these help to polarize an organisation and bring about low staff moral and low productivity - evidences of leadership ineffectiveness.

Table 4 Relative contribution of professionalism to the determination of leadership effectiveness

\begin{tabular}{|c|c|c|c|c|c|}
\hline B & SEB & Beta & T-Ratio & p & RMK \\
\hline 0.316 & 0.066 & 0.114 & 4.769 & 0.000 & $\mathrm{~S}^{*}$ \\
\hline \multicolumn{2}{r}{$\mathrm{S} \rightarrow$ Significant at $\mathrm{p}<0.05 ;{ }^{*}$ NS $\rightarrow$ Significant at $\mathrm{p}>0.05$} \\
\end{tabular}

Table 4 reveals that the b-value of professionalism is 0.316 , which shows the level of its contribution to the determination of leadership effectiveness. While its standardized regression weight (Beta) is 0.114 indicating the level of relationship between the determinant variable and leadership effectiveness. The $t=4.769$ which is statistically significant at $\square=0.000$. Since 0.000 $<0.05$, the null hypothesis is therefore rejected in favour of an alternative hypothesis which states that professionalism will significantly determine leadership effectiveness in the Nigerian sports industry.

This finding is in consonance with the position of Wuest and Bucher (1999) that effective leaders must have technical mastery of the organisation or profession they are leading. In other words, they must know the process by which goals are achieved and must understand how each person's task fits into the total enterprise. Similarly, Karen (2003) postulated that being technically proficient usually makes an administrator standout as one of the grates. A great administrator needs to know his field because this in no small measure promotes the effectiveness of a leader. 
Horine (1999) in support of this finding submitted that technical skills are certainly necessary if a leader is to be highly effective.

Warren (2000) in line with the finding of this study submitted that being technically proficient implies that a leader must know his job and have a solid familiarity with his employees' job to be effective. The finding of this study and the submissions of the authors cited affirm that an effective leader should be versatile in all the departments of the organisation he provides leadership for. This assertion points to the fact that the idea of putting "round pegs in square holes" in the administration of sports is one of the reasons for the dwindling fortune of sports in Nigeria.

\section{Conclusion}

This study attempted to investigate the determinants of leaderqhip effectiveness in Nigeria sports industry. Four hypotheses were tested out of which three webe rejected while the remaining one was accepted. The findings of the study revealed that Intelligence, integrity and professionalism are potent in the determination of leadership effectiveness in Nigerian sports industry, while integration is not.

Based on these findings, those in leadership positions in Nigerian industry should as a matter on necessity possess the leadership traits investigated in this study for their effectiveness to be enhanced.

\section{References}

Adair, J. (2002)." Effective strategic leadership" In V, Koteinikov (Ed.), Effective leadership. Australia: Tech Republic.

Adesanya, A.O (1989) Relationship between sports facilities and participation in selected Nigerian universities. Unpublished PhD thesiS, Ibadan: University of Ibadan

Ajiduah, A.O. (2001). Revitalizing sports in Nigeria: Practices, problees and prospects. Reports of National Committee on Problems on Sports Development in Nigeria. 3, 37-57.

Akintunde, P.G. (2001). Administration and organisation of physical and health education, sports and recreation. 1, Ibadan: Yew Printers.

Asagba, B.O.(1992) Evaluation of intramural sports programs and programming in Nigerian colleges of education. Unpublished PhD thesis, Ibadan: University of Ibadan

Awosika, Y. (1995). The need for effective management of physical training and sports in Nigeria. A paper presented at the Directorate of Army Physical and School

Babajide, E.O. (2000). A comparative analysis of leadership styles of male and female management in banking industries in South Western Nigeria. Unpublished PhD thesis, Ibadan: University of Ibadan.

Bennis, W. (1995). Learning about leadership. USA: University System News. 5, (2), 5,9, \&10.

Fasan,C.O. (1989) Organisational, development and success predictability in sports administration in selected sports council in Nigeria. Unpublished PhD thesis, Ibadan: University of Ibadan. 
Fred, S. (1996). Leadership Journal, 17 , (4), 2-3

Gordon, T. (2002). "Effective strategic leadership" In V, Koteinikov (Ed.) Effective leadership. Australia; Tech Republic, Inc.

Horine. L. (1999). Administration of physical education and sports programs. (4th ed). USA: McGraw-Hill.

Ikhioya, O.S.A. (2001). Functional strategies for effective sports management practices: Guides for sports managers and administrators. Lagos: Sports \& Leisure Consults

Ipinmoroti, O.A. (2000). Determinants of coach leadership behavior in selected sports councils in Nigeria. Unpublished PhD thesis, Ibadan; University of Ibadan.

Ituh, M.C. (1992). Qualities of administrators of physical education programme in school or college. Journal of Nigeria Academy of Sports Administration, 1, (1\&2), 14-18.

Karen, A.R. (2003). Top ten leadership qualities of successful CIOs. Australia: Tech Republic, Inc

McNamara, C. (1999). Overview of leadership in organisations. Nut-and-Bolts Guide to leadership and supervision. New York: Amazon Com

Omolawon, K.O. (2000). Evaluation of sports programme delivery system in selected universities in south western Nigeria. Unpublished PhD thesis, Ibadan: University of Ibadan

Orunaboka,T.T.(1998) Evaluation of sports programme implementation and achievement of rivers state at national sports festival. Unpublished $\mathrm{PhD}$ thesis, Ibadan: University of Ibadan

Warren, B. (2000). Becoming a leader. Big Dog's leadership page- concept of leadership. http://www.nwlink. Com/ donclark/leader/leadcon. Html

Wuest, D.A. \& Bucher, C.A (1999) Foundation of physical education and sports. (13th ed.) New York. McGraw-Hill Company. 